\title{
Programa de residência multiprofissional em saúde: fortalecendo a integração profissional em contextos reais de aprendizagem
}

Alessandra dos Santos Tavares Vieira, Daniela Silva da Silveira, Ana Michelle Castro da Silva Holanda, Liliane Silva do Nascimento

\section{Resumo}

Introdução: Historicamente, constata-se as inúmeras tentativas de alterar a forma que os serviços de saúde são ofertados, extremamente curativista e mutilador, além de considerar a saúde de forma isolada, altamente especializada e pouco humanizada. Diante disso o Sistema Único de Saúde (SUS) juntamente com o Ministério da Saúde (MS) e Ministério da Educação (MEC) propuseram o Programas de Residências Multiprofissionais responsáveis por qualificar os recursos humanos com objetivo de promover atenção à saúde da população em equipe a qual pertence vários profissionais. Objetivos: Relatar a experiência vivenciada pelos residentes do Programa de Residência Multiprofissional em Saúde da Família de Belém - PA Métodos: O programa de residência é uma modalidade de pós-graduação lato sensu. No estado do Pará contempla atualmente as categorias profissionais de enfermagem, fisioterapia, terapia ocupacional e odontologia. Preconiza pelo nível de assistência da Atenção primária, compreendendo em teoria com eixos específicos, transversais e comum, e também em prático, onde no primeiro momento somos inseridos na assistência e em outro na gestão desses serviços, onde as atividades são realizadas com todos os diferentes profissionais que compõem o programa de residência. Resultados: A vivência proporcionada pela residência fez com que conseguíssemos compreender sobre as especificidades de cada profissional bem como sua importância. Além de nos fazer repensar nossa prática até o momento baseada na graduação com enfoque quase que exclusivamente curativista, além de termos tido a oportunidade de estarmos em contato com a realidade sociocultural e do próprio serviço de saúde ofertado. Conclusões: A residência multiprofissional em saúde é importante por proporcionar uma formação de profissionais para o sistema de saúde, transformando sua visão para a o trabalho em equipe e sobretudo na atenção das ações voltadas para o cuidado e valorização do autocuidado em saúde da população.

Descritores: Educação em saúde, Residência multiprofissional, Atenção primária 